\title{
Mission accomplished...it's leapnable now: Voices of mature challenged spellers using a Word Study approach
}

\section{Donita Massengill}

Adult poor spellers were provided instruction in Word Study, a spelling approach that has worked well with adults. The participants' knowledge of word features increased as did their confidence and self-esteem. teacher stood up and said, "One person was so stupid on the test that she spelled heart wrong. She spelled it this way." Vicki couldn't remember
Massengill teaches at the University of Kansas in Lawrence. She may be contacted there at 1122 West Campus Road, 449 J.R. Pearson Hall, Lawrence, KS 66045, USA. E-mail to donita@ku.edu. how she spelled heart, but she said the fact that her teacher told the entire class about her mistake was a very humiliating experience. Moreover, Vicki said she was always the first one to sit down in a spelling bee. David, too, spoke painfully as he shared a spelling bee memory. He was in sixth grade, the third student in line. The teacher asked David to spell first, and he could not spell it correctly, so he was the first person to sit down. Charles's parents were educators; his mother was a principal and his father a first-grade teacher. He spoke of the nights spent in the kitchen doing his homework, of the fights with his father, of throwing pencils and paper and crying a lot. Charles's memories were vivid. He said, "My memories are just like I said; I've never thought about it until right here and now, and then boom, they're back like I'm right there. I could tell you everything about the kitchen."

I was interested in learning about the spelling instruction these adults received during elementary school. Tina said it was

spelling by memorization. I ran into all my old grade cards from elementary school, including some of my 
spelling books. And as I was looking through those from the third grade, there's no rhyme or reason [to the list of words]. It's a story with 20 or 30 words.

Kathy remembered "a lot of words to memorize and spelling bees...some basic rules like $i$ before $e$ except after $c$." She also remembered mnemonics; for example, geography could be remembered by "George's eldest oldest girl...." Elizabeth said she remembered "getting a list of 20 words every week and then having a test every Friday over the words and just having to memorize them." Elizabeth said her parents (her mother is a university professor) worked with her often by giving her practice tests where she had to write each word 10 times. Sam's parents also stressed "repetition...you have to repeat the words over and over." I purposely asked each individual if they could recall their teacher instructing them in spelling, and not one could call to mind having been "taught" to spell.

For years, spelling has been considered a rote memorization process (Schlagal, 2002). Yet research has shown that memorization is not sufficient for learning to spell (Bloodgood, 1991) and that individuals' orthography can be strengthened as they increase their knowledge about the structure of words. Interactive Word Study is a practical approach that has been founded on orthographic research (Bear, Invernizzi, Templeton, \& Johnston, 2004; Ganske, 2001). Word Study is a method for teaching literacy skills by requiring learners "to examine, discriminate and make critical judgments about speech sounds, word structures, spelling patterns, and meanings" (Bear et al., p. 3). It is a respected spelling approach that has been widely used in teaching children for more than a decade, and it is based on a developmental philosophy that learners' spelling progresses through predictable stages over time.

Historically, research on spelling has lagged behind research on reading. Even though the gap has narrowed in recent years, we still know less about learners' processes of spelling than reading.
Unfortunately, only a handful of studies have been published on adult spelling. The present study was designed to fill gaps in our knowledge about adult orthography. It was the purpose of this research to evaluate the impact of an instructional spelling approach-Word Study (Bear et al., 2004)—on adult learners' spelling. I sought to learn more about adults' stages of spelling development, to gain information from the participating adults on their interpretations of this approach, and to determine if a short-term intervention would improve their spelling or selfperception.

\section{Laying the groundwork}

The earliest method of spelling instruction required students to memorize numerous words in list form. New memorization strategies were introduced in the 1930s and 1940s in order to assist learners in mastering words for the weekly spelling test. During the 1960s, the first analysis of spelling generalizations (Hanna, Hanna, Hodges, \& Rudorf, 1966) discovered a surprising amount of consistency in the English orthographical system. This finding influenced a change in the lists of words provided for students; selection was now based on spelling patterns. Two relevant landmark studies took place in the 1970s when Chomsky (1970) and Read (1971) began to investigate young children's invented spelling. Their results led to the conclusion that children have an innate ability to learn language, and they construct and use knowledge about letter-sound relationships. This understanding became the foundation of developmental stage theory (Henderson \& Beers, 1980), which is the conceptual framework of the Word Study approach (Bear et al., 2004). It is believed that learners progress through stages of development that are based on the three tiers of English orthography: alphabet (sound-letter correspondence), pattern (complex grouping of letters), and meaning (derivations of words). 
The five stages of spelling development that progress through the three tiers of orthography are called emergent, letter name, within word, syllables and affixes, and derivational relations. Emergent spellers learn some letter-sound matches and develop their understanding of directionality. Letter-name spellers solidify their letter-sound knowledge, including consonants, short vowels, and most consonant blends and digraphs. Students in the within-word spelling stage learn long-vowel markers, ambiguous vowels, and complex consonant clusters in onesyllable words. Syllables-and-affixes learners begin to experiment with consonant doubling, suffixes and prefixes, and vowel and consonant alternations in multisyllable words. The final stage, derivational relations, instructs learners to spell most words correctly and to expand their vocabulary by mastering derived Greek and Latin roots. Within each of these five stages, there is a progression of knowledge about word features that can be identified as early, middle, or late.

It has been asserted that learners advance through a sequential process of knowledge about word features, and that students should receive spelling instruction according to their developmental level (Bear et al., 2004; Bloodgood, 1991). Further, students should be active in the examination of words that have been selected by the teacher for instruction (Bloodgood; Templeton \& Morris, 1999). The Word Study approach includes active manipulation of words-for example, sorting words to compare and contrast features - and this, in turn, allows students to internalize and generalize word features. Bear et al. deemed this word analysis to be superior to the act of memorization because spelling is an active process, not a passive one. Furthermore, the complex English language may become orderly to learners who cognitively map new levels of words based on words they know, use, and examine. In this manner, spelling is a concrete process, not an abstract one (Henderson \& Templeton, 1986).

In contrast to the developmental approach, a traditional basal speller approach has a set structure. Weekly word lists and varying daily activities are predetermined. Most of the activities do not engage students in manipulating and categorizing words. Instead, the activities are often related to vague language arts goals. These activities may include unscrambling words, alphabetizing words, writing words three times, finding words in the dictionary, or using the words in a sentence. While these requirements may assist students in learning related skills, none of these activities have research support to promote spelling achievement (Morris, Blanton, Blanton, \& Perney, 1995; Schlagal, 2002). Further, the words studied each week vary, depending on the basal spelling program that is used. For example, some programs choose words that students will read in their basal reader. Other programs select high-frequency words that students encounter in a variety of texts, and some other programs choose words that combine one of the aforementioned approaches with words having similar phonetic features. This lack of consistency of selected words across programs and the dearth of research support suggest that a traditional basal speller approach that requires rote memorization may no longer be the best technique for teaching spelling. Teachers have often said that students can memorize words for their spelling test but they are unable to spell those same words correctly in their writing the following week (Gill, 1996); the transfer and carry-over of knowledge is lacking (Zutell, 1978). Memorization alone does not seem to an effective enough method for learning words, which is the true goal of spelling.

Most adults were instructed in elementary school through the use of these traditional spelling methods that promoted rote memorization. Although spelling research on adults is sparse, two studies have contributed to our knowledge about the orthographic skills of adults. A pioneering study was published in 1989 by Bear, Truex, and Barone, who found that adult spelling development mirrors the patterns identified in children's progression. In 1996, Worthy and Viise also confirmed that the developmental stage theory applied to adults. 
Of the five developmental stages, Bear et al. (2004) stated that approximately $25 \%$ of the adult population is stunted at the third stage of orthographic development, the within-word stage. The focus of instruction in the within-word stage is the multiple vowel patterns in singlesyllable words such as long vowels, ambiguous vowels, and $r$-controlled vowels. Bear and his colleagues advocated that community college and university students who were poor spellers should receive instruction in vowel patterns. These learners were adults capable of reading short sight words but who had great difficulty reading uncommon multisyllable words and especially struggled with the conventional spellings of multisyllable words in their writing, such as sailor, fever, nuisance, confident, fortunate, dominant, and voluminous.

Worthy and Viise (1996) and Viise (1996) investigated spelling similarities and differences among adults and children, finding similarities in spelling patterns (number and types of errors). The adults appeared to have more advanced orthographic knowledge than the children yet weaker phonological skills. Worthy and Viise's recommendation was to engage adult learners in direct instruction that focuses on linguistic analysis, as Word Study does. Viise strongly recommended continued research in the area of effective instruction so as to increase the adult students' chances for success.

Hanlon and Cantrell (1999) have documented use of Word Study with a 31-year-old male (Tom) who had a learning disability. By receiving appropriate words at his instructional level and performing active, critical-thinking Word Study activities, Tom made remarkable gains in spelling as well as in his reading level during the nine-month study. Adults who have experienced years of frustration and failure have been successful when instruction was adjusted to their developmental needs (Hanlon \& Cantrell, 1999; Viise, 1996).

In planning for effective instructional practices for adults, three principles for adult literacy instruction (Padak \& Padak, 1987) should be considered. First, theoretical knowledge about literacy and the processes of literacy should underlie instruction. Second, adults' affective needs should be addressed through instructional processes, and third, instruction should maximize learner satisfaction. Word Study has the potential to deliver on all of these, with support indicating that basic approaches used with children and adolescents can be equally effective with adults (Chall, 1994) when the adults' needs (Kitz, 1988), interest, knowledge, and motivation (Greenberg, 1998) are considered during instruction.

Instruction that is sensitive to the special needs of adult learners can include the same Word Study strategies.

In sum, research has shown a need to teach spelling to students at their developmental level and provide opportunities for them to learn words through active, exploratory approaches. Research comparing adult and child orthographic development and knowledge has indicated that there are many similarities and that adults can benefit from Word Study. Several researchers have supported the notion that basic literacy approaches used with children may be not only acceptable but also effective with adults, as long as adults' specific needs are considered. Word Study is a researched approach that deserves attention and analysis in the field of adult literacy. Because there is a lack of research in the area of adult spelling instruction, this article will make a contribution to the field.

\section{The participants}

The participants in this study were recruited by an advertisement placed in the local newspaper for four days. I was surprised that 25 adults wanted to participate in the study. Originally I had planned for 10, and because I was not able to find more tutors to meet the needs of these 25 adults, I had to turn many away. The participants were selected on a first-come basis; there was no discrimination based on spelling or reading ability, race, 
gender, or age. Ten participants began the study, but one dropped out at the beginning due to personal issues.

Elizabeth was a Caucasian female, age 19, who attended the local university with a double major in math and economics. Sam, a 23-yearold male Caucasian, graduated in May 2004 with an undergraduate degree in professional relations from the university. Kim was 39 years of age, Caucasian, and practiced massage therapy. Chloe, a Caucasian 37-year-old mother of two young children, held a master's degree in social welfare. David, the eldest participant at 62 years of age, was a successful Caucasian sales representative. Charles was a multiethnic 28-year-old university journalism student. Tina, a 52-year-old Caucasian, had a master's degree in business administration and worked successfully for a large national corporation for many years. Kathy, a Caucasian female 41 years of age, held an associate director position at the university. Vicki, a 49year-old Caucasian college graduate, was raising her grandchildren.

Elizabeth's pretest (total of 32 words correct out of 40) showed that she was a middle derivational-relations speller. Sam (24 words correct) was a middle syllables-and-affixes speller. Kim ( 29 words correct) spelled at a late syllablesand-affixes stage. Chloe's spelling ( 25 words correct) indicated knowledge of syllables and affixes at the middle part of the stage. David scored in the middle syllables-and-affixes stage with 17 words correct. Charles was a late syllables-andaffixes speller at pretest, with 26 words correct. Tina (27 words correct) was also a late syllablesand-affixes speller. Kathy's pretest indicated that she, too, was a late syllables-and-affixes speller with 26 words correct. Vicki (14 words correct) was a middle syllables-and-affixes speller.

As can be seen, the ages of the participants varied from 19 years of age to 62 years. All but Charles were Caucasian. The nine participants were middle class individuals who held college degrees (or were pursuing them). Four individuals scored in the middle syllables-and-affixes stage, four participants' spelling indicated their understanding of late syllables and affixes, and one adult was placed in the derivational-relations stage.

\section{The procedures}

After the adults were recruited, they came for an interview and pretesting. I administered three assessments: The Test of Written Spelling (1999), a standardized spelling test; the Words Their Way upper level spelling inventory (Bear et al., 2004); and the Slosson Oral Reading Test-Revised (1990). The reading assessment was administered as a screening of the participants' reading levels because spelling and reading are two closely related processes that rely on word knowledge (Ehri, 1997) and also to determine whether changes in spelling ability might affect reading ability. The two spelling assessments were analyzed for specific features (e.g., vowel patterns, doubling, roots) within words to determine instructional needs. For example, if the participant spelled scrape as scrap, one of the lessons focused on the silent- $e$ pattern.

Two trained, qualified graduate students delivered the instruction with my supervision. Carissa tutored six adult participants, and Kaela tutored three participants. Both Carissa and Kaela met the adults two times per week for approximately 20 minutes. The lessons consisted of several steps: assessment of the previous lesson's words, introduction of a new word sort, and performance of the word sort by the adult learner who then stated the generalization or pattern. The adult learners were asked to practice sorting the words at home to become more automatic, to look for words in their reading or work that contained the generalization or pattern, and to actively engage in learning in the manner they knew best. All lesson materials were taken from Words Their Way (Bear et al., 2004) or Word Journeys (Ganske, 2001).

The intervention was scheduled for 12 spelling sessions. Only three of the participants (Tina, Vicki, Chloe) attended all 12 sessions. After the spelling sessions the adult participants met 


\begin{tabular}{|c|c|c|c|c|c|c|}
\hline \multirow[t]{3}{*}{ R a w } & \multirow{2}{*}{\multicolumn{2}{|c|}{$\begin{array}{c}\text { s cor es a nd means } \\
\text { Slosson Oral Reading } \\
\text { Test-Revised }^{\mathrm{a}}\end{array}$}} & \multirow{2}{*}{\multicolumn{4}{|c|}{ 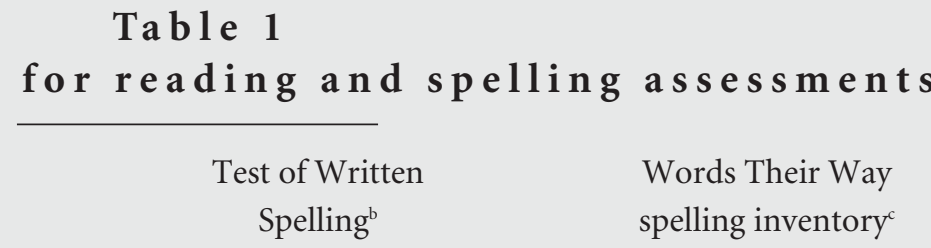 }} \\
\hline & & & & & & \\
\hline & Pretest & Posttest & Pretest & Posttest & Pretest & Posttest \\
\hline Vicki & 198 & 198 & 30 & 32 & 14 & 18 \\
\hline Kathy & 200 & 199 & 42 & 40 & 26 & 29 \\
\hline David & 186 & 187 & 24 & 22 & 17 & 16 \\
\hline Chloe & 195 & 196 & 31 & 36 & 25 & 26 \\
\hline Kim & 197 & 196 & 42 & 40 & 29 & 29 \\
\hline Sam & 198 & 198 & 39 & 41 & 24 & 25 \\
\hline Elizabeth & 199 & 199 & 40 & 45 & 32 & 31 \\
\hline Charles & 193 & 196 & 36 & 38 & 26 & 29 \\
\hline Tina & 200 & 200 & 39 & 41 & 27 & 27 \\
\hline Mean & 196.22 & 196.67 & 35.89 & 37.22 & 24.44 & 25.56 \\
\hline $\begin{array}{r}\text { Note. }{ }^{\mathrm{a}} 200 \\
{ }^{\mathrm{b}} 50 \mathrm{p} \\
{ }^{\mathrm{c}} 40 \mathrm{p}\end{array}$ & $\begin{array}{l}\text { points possible } \\
\text { oints possible } \\
\text { oints possible }\end{array}$ & & & & & \\
\hline
\end{tabular}

individually for another interview and posttesting. The posttests were identical to the pretests.

\section{Searching for answers}

The purpose of this study was to determine if Word Study (Bear et al., 2004) positively affected adult learners' spelling and concept of themselves as spellers during a short-term summer intervention. First, the quantitative data of the pre- and posttests will be reported, followed by analysis of the interviews to determine themes and patterns, and finally a qualitative data review.

The nine participants' pre- and posttest scores for the three assessments can be found in Table 1. On the Slosson Oral Reading Test-Revised (1990), there were a total of 200 words for the adults to read and, therefore, 200 points possible. As can be seen, the participants' scores indicated they were good readers. Of the 200 words, two words challenged the participants most: deprecate was most commonly read depreci- ate, and envisage was often pronounced with an incorrect final syllable or accent. David had the greatest difficulty with reading. Some of his errors include compressionable for compressible, remisciment for reminiscence, charisma for chastisement, and inadequate for inadequacy. The mean scores for pre- and post-Slosson Oral Reading Test-Revised show consistency, with a slight four tenths gain after intervention.

The Test of Written Spelling had 50 possible points, 1 point per word. The highest pretest score was 42 points, with the average score 35.89 points, indicating the participants spelled approximately $70 \%$ of the words correctly. Six of the nine participants increased in their posttest score, raising the mean 1.33 words. A paired-samples $t$ test for statistical purposes was run, suggesting that the learners' spelling level did not improve significantly after the 12 spelling lessons $(M=$ $1.33), t(8)=1.44, p<.19$.

Bear et al. (2004) provided an upper level spelling inventory that was administered to 
Table 2

Feature/raw scores and means for spelling inventory

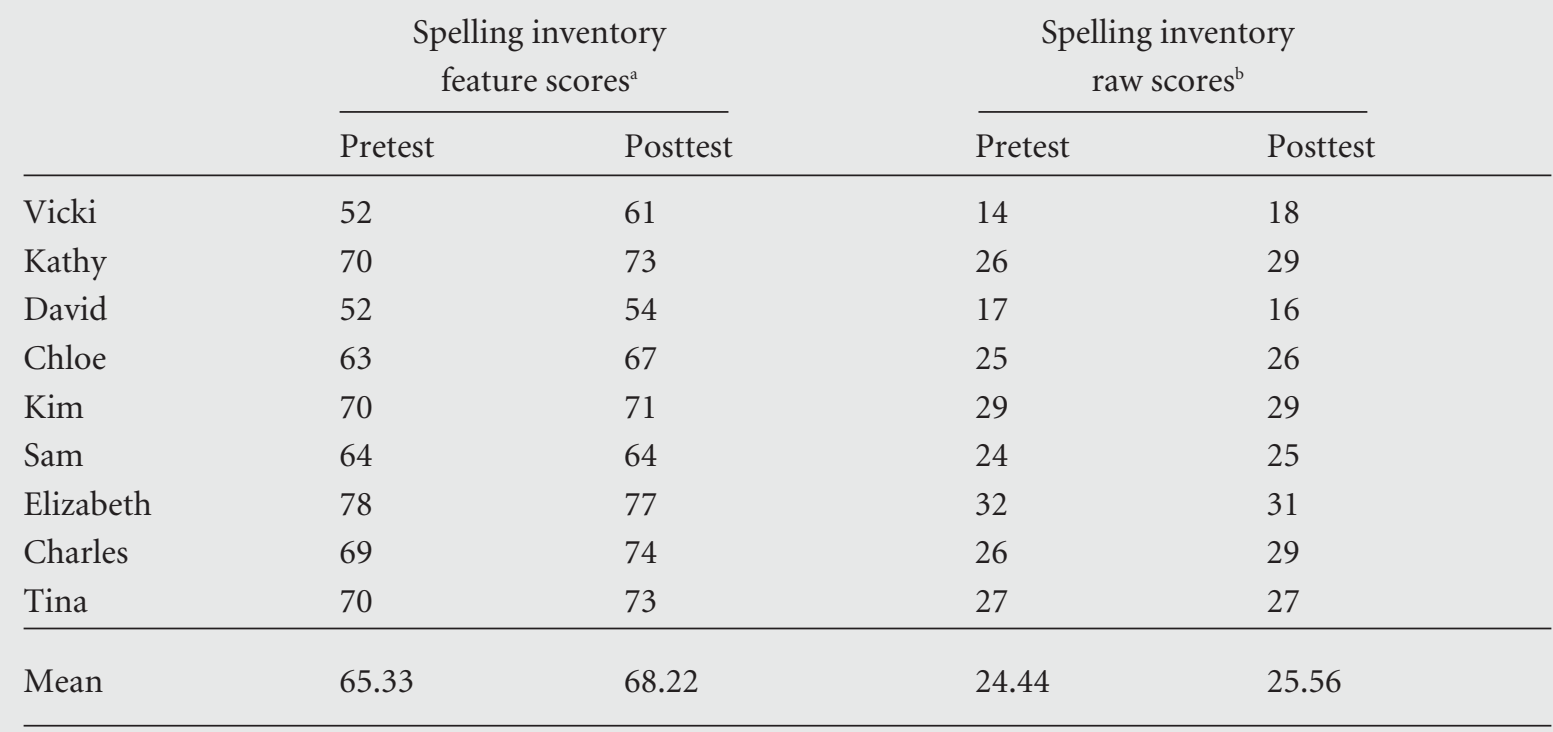

Note. ${ }^{a}$ The correct spelling features of words, 126 features total

b The total number of words spelled correctly, 40 words total

determine the participants' knowledge of spelling features. Out of 40 words, the average pretest score was 24 words spelled correctly (which was $60 \%$ ), with an increase to 25.56 words spelled correctly for the posttest. Again the results were not significant $(M=1.11), t(8)=1.82, p<.11$. Two participants' scores remained identical and two slightly decreased, while the remaining five participants' scores showed a positive result.

While the pre- and posttest raw scores are not particularly telling, it should be noted that the tutors did not "teach to the test." The misspelled features on the pretests were the focus of the lessons. All nine learners needed to work on their suffixes (such as -ible/able) and reduced and altered vowels. Several (ranging from three to five participants) needed some basic foundation, work on silent $e$, long vowels, hard or soft $c$ and $g$, complex consonant clusters, and the doubling rule. At each session the adult spellers were given a word sort based on one of these concepts. At the following session the learner was tested on the words and the pattern. When the tutor said the word, the learner had to spell the word correctly and place it in the correct column (e.g. -ible words in one column, -able in another column); therefore, two points were possible for each word. Most participants scored well on the spelling tests; the deductions were usually only 1 or 2 points. Occasionally, the adult learner would tell the tutor that the words were easy. However, it was the generalization or pattern of the words that needed to be mastered and, as can be seen, the weekly tests challenged the adult spellers to think about the word's features.

To answer my inquiry about whether the adults' knowledge of spelling features was affected, I completed feature guides (Bear et al., 2004) for the pre- and posttests. Feature guides list key orthographic patterns across the developmental stages, and participants' spelling can be analyzed for the total number of known features. Table 2 displays the participants' scores for the features and their raw score for the Words Their Way upper level spelling inventory (Bear et al.). Out of 126 total features, the participants' average pretest feature score was 65.33 , which was $54 \%$ correct. A paired-samples $t$ test for statistical purposes 
found the learners' spelling-feature knowledge significantly improved after the 12 lessons $(M=$ 2.89), $t(8)=2.91, p<.02$.

Of great interest are the perceptions and interpretations of this experience for the adult learners. At the beginning of the study, not one had heard of "Word Study." Let me share their comments from before and after the intervention.

\section{Participants' interview comments}

When asked why they chose to be a part of this study, each of the nine participants said he or she believed he or she was a poor speller. The introductory quotes in this article speak for these individuals. Moreover, Chloe said, "There has been a gap in my learning.... It [spelling] isn't one of my strengths." These nine learners took a risk to participate. A few feared they would be rejected from the study after completing the pretests.

Spell-check appeared to be a lifesaver for these individuals. All mentioned spell-check as a way to assist them through their required writings. In many ways spell-check is a crutch. Charles said he will not use the university's e-mail system because it does not have a spell-check. Kathy, Chloe, Sam, and Kim said they are often frustrated with spell-check because their words, on occasion, were not close enough for spellcheck to help them. Sam said he might "stumble around for 10 minutes with spell-check trying to get it to work." Kim said, "I'll try to type it four different ways before it will even register." Other ways they coped with their limited spelling ability were to mask poor spelling with illegible handwriting, carry a dictionary with them, ask someone how to spell a word, find someone to do the writing for them, or change their original message to contain words they knew how to spell.

I learned from the initial interview that all nine participants felt frustration and humiliation about their spelling. Some of these experiences resulted from hurtful words spoken to them, moments when they made a spelling mistake and sensed failure, or years of effort in rewriting and memorizing words with little gain in their orthographic knowledge. All of them found ways to accomplish their required writing, and they joined in this research study to learn more about words and to improve their spelling.

I began the final interview by asking the participants if they had learned anything and if so, what they had learned. Eight said they learned to recognize some patterns, how some words were put together, and how to pay more attention to word features. Kim and Charles shared an "aha!" moment- they learned to spell stopping by learning when to double a consonant before the suffix. Tina said, "For the first time, I feel like there is a process behind spelling." Vicki was the only participant who did not mention any patterns or lessons. However, she stated, "I think that I have learned that if I had been taught this way in school, I might have picked it up [spelling].... I don't ever remember there being a pattern to what spelling list you were given; it was just arbitrary. Or if there was a pattern, they never bothered to point it out."

The participants were asked to articulate if their spelling had changed and, if so, how it had changed. Vicki said that her spelling had not changed because the lessons went too fast; the lesson should be similar for at least two sessions and there should be lots of repetition. The remaining eight participants said they felt their spelling had improved. Obviously their improvements in a short amount of time register as small advances (as measured on the pre- and postassessments), but they felt their spelling had changed in certain ways. David said, "I feel a bit more confident about some of the words that I was frightened to use before, but I can use them now." "I know when I'm spelling a word wrong, whereas before I didn't know I was even spelling it wrong," said Chloe. "If I come to a word that I don't know how to spell I actually reason it out a little more carefully, whereas before I would just be like, I'm not sure how to spell this, I'll just guess," stated Kathy. The adults who felt their spelling changed thought they were more conscious of words, had greater confidence 
in spelling some words they previously avoided, believed they had tools to figure out how to spell a word rather than just "guess," and had an improved ability to know whether a word was spelled correctly or incorrectly.

Every one of them found the active sorting to be beneficial. David and Vicki did not like the sorting at first because it was a completely new and different way to learn to spell, and it was a two-step process, with the second step being the most challenging. David said, "The first night I was completely snowed...because I'm doing two things: I'm learning a word plus putting it in a category." However, even Vicki and David said they grew to appreciate the sorting. As Chloe said, the sorting "was fairly easy. The hard part was trying to figure out why they [the words] went there." However challenging it may be, the adults believed it helped them learn the words. Chloe went on to say, "It made the rule applicable right away. I could see where it made sense right away." Elizabeth said, "I would maybe sort them once during the week, but I didn't really pay attention to memorizing the spelling of the words, and I was kind of surprised that that worked, that I could spell without having to memorize." Sam said, "It's easy to see how a lot of words have the same basic characteristics so you can get a handle on them." Tina spoke, "I think I liked it because it focused on what I consider to be the primary learning modalities for adults, being both visual and kinesthetic. I mean you have to do it, you're writing, reinforcing it, making me think, having conversations, so I was hitting on both interpersonal and intrapersonal."

I wanted to learn how the participants perceived the session format and timing. Most of the participants seemed to feel the format and timing was adequate and they didn't have any specific recommendations or ideas for improvement. Charles said, "I think in 30 minutes or less, I think I've retained a lot. I think the repetition and how it builds, so we did this last week, or just adding on to what we did, is a strength of this approach."
Their self-study and ability to apply their learning was of special interest to me. I found that seven of the adults studied between sessions. The participants led busy lives but tried to squeeze in a few minutes of review whenever possible. An example was Charles, who had a very demanding summer with his college classes, but he said he would often take his words with him, even to places such as fraternity recruitment, or he would look at his words before he'd take a shower or go to bed. David, Kim, and Tina studied a lot between sessions. Kim said she faithfully re-sorted and wrote the words and had a friend or relative give her a practice test. She said, "the process of writing it down and putting it into the right category" was the most helpful study strategy. Two participants, Sam and Vicki, did not appear to take the time for independent studying. As a result, they seemed to experience difficulty in making a connection between their practice lessons and their daily spelling and writing. Vicki admitted she wanted a "quick fix." The seven who reported effort and study indicated they could transfer the learning of the specific lessons to their daily writing and felt empowered as a result of their knowledge. David said, "I've got a way that I can learn. I can teach myself." Kathy said, "It's something that I can take forward and practice in other situations, not just on that one word I've memorized." This application was the goal of this short-term intervention.

To conclude my presentation of the results of this study, I will share a few final comments. Charles reflected, "And looking back on it the first day I came here, I would not have imagined it ending up like this. If I can just spell one word better, it was worth it. It's been a valuable experience." Tina explained, "I liked it; it was great. I'd recommend this for anybody." At the beginning of the study Kathy set a goal to "feel more comfortable with spelling." When I asked her how she felt about this goal after the intervention, her answer was noteworthy. Kathy said, "Mission accomplished. Yeah, I mean, I feel I still have a lot to learn but I feel like it's learnable now." Later in the interview Kathy was asked how much she felt she 
had learned and her response was, "A lot. Maybe what I have learned is not as much as the confidence I have. That is a tremendous boost."

\section{The meaning}

The results of this study are limited due to the small number of participants, the short duration, and the fact that a direct causal link cannot be made between the participants' scores and their success and retention. The quantitative assessments showed slight gains, and the weekly tests indicated mastery of the concepts. The qualitative findings, in particular, suggest that Word Study appears to be a valuable method for teaching spelling to adults.

Previous researchers Bear et al. (1989) and Worthy and Viise (1996) found that adults' spelling errors can be categorized into developmental stages that reflect the orthographical knowledge and stages of children. In this study, the adults' spelling represented the two latest stages: syllables and affixes and derivational relations. It has been recommended that a knowledgeable teacher should select appropriate words (Templeton \& Morris, 1999) and that learners should be active in their study of the word features (Bloodgood, 1991; Templeton \& Morris). These suggestions were heeded in this study. When adults received instruction at an appropriate level through a method that promoted thinking, internalizing, and developing generalizations rather than memorizing, the learners became more successful (Hanlon \& Cantrell, 1999; Viise, 1996).

Now that the study is complete, I ask myself, "What does all this mean for me as a teacher and researcher?" First, there are many adults who are disheartened about their poor spelling, across all ages, ethnicities, and educational experiences. Their self-esteem is clearly affected by what they believe is a great limitation to their ability to effectively communicate. While limited in their spelling, many of these adults are actually quite motivated to improve. So, second, we should at- tempt to provide services for spelling. An interested seeker can find adult classes in many areas of literacy, yet spelling is rarely, if ever, offered. Even in professional workplaces, a course on spelling would be an enhancement. Perhaps we don't offer "spelling instruction" because it seems like too elementary a skill, or because what instructors know to teach is more of the same, traditional, and not a method that has been shown to be successful for many adults. Regardless, this study has convinced me of the need to offer adult spelling instruction. This brings me to my third point. Viise (1996) asked, "Can we identify instructional practices that will be most effective in helping our adult learners to overcome their variety of difficulties and progress in their learning goals?" (p. 581). I believe we can answer the question in the affirmative. All of the participants said the sorting was beneficial: the self-discovery, the analytical style of comparing and contrasting word features, the search for exceptions, and the thinking critically about words. Their voices, as revealed earlier, indicate that they would approve Word Study as an approach for adults. This method made them more conscious of word features, patterns, and generalizations and gave them a tool to better determine the spelling of words.

Some lessons were learned that may assist educators who are interested in using this approach with adult students. Adults should take charge of their education, study at home, and try to apply their learning in new situations.

However, while some of the adults attempted this, most wanted and needed support. The majority of the participants said they needed to be told to record their lessons. It would be most beneficial if the adults would be required to write down their words and the generalizations in a notebook for future reference. If they are not held accountable in this way, they may not take the time to reinforce their efforts. The adults should be required to search for words with similar patterns in their reading or writing (this activity is called a word hunt) which may aid in transferring knowledge, seeing generalizations in multiple words, and making the connection between their learning 
and their daily literacy tasks. The words found during the word hunt should also be collected in their notebook. The instructor will need to monitor the notebook and provide feedback for the adult learner on a regular basis. The instructor should explicitly model how to keep the notebook (Roehler \& Cantlon, 1997), how to find words in a word hunt, and how to think about the features of words. This modeling of procedures and thought processes should be done in a mature way to scaffold the thinking tasks so that the adult will learn how to teach himself or herself.

Another suggestion is that adults should keep a list of the times when they spell a word correctly in their daily writing as a result of their informed learning in the study. This activity would serve three purposes. First, it would allow adults to see the association between a lesson and their daily life. Second, as the list grows and they become aware of their increased correct spelling of words, their confidence will rise. Third, when individuals write the word, they retain the information more effectively in their minds. Writing allows access to the kinesthetic pathway, which is a strong, reliable learning channel (Sheffield, 2003; Zaporozhets \& Elkonin, 1971).

The aforementioned ideas should assist retention. However, Vicki made the point that she would benefit from repetition of the concepts during the lessons. One way to do this is through the transfer activities at each session. Even though the majority of the words on their test should come from the new material given at the previous session, words from previous spelling tests may be given to aid review, keep the generalizations fresh in their minds, and measure their retention.

Before conducting this study, I debated whether I should show the Words Their Way video (Bear, Invernizzi, Templeton, \& Johnston, 2000 ) to provide the adults with an understanding of this Word Study approach. Instead of viewing the video, I explained to the adults what we have learned about patterns and generalizations in the English language and that spelling errors are not random but an indication of the learner's orthographic knowledge as he or she progresses through stages. I also told the adults they would be active in their discovery of words in a handson manner through a brain-based approach. In retrospect, if I continued this research I would show the introduction to the Words Their Way video (Bear et al.) to help the adults see the rationale behind this method, to learn visually about the three layers of orthography, and to understand how this spelling approach will benefit them. Even though the video is of children, I believe it can be supplemented with information about adult spellers, such as the comments of the adults in this study. I believe previewing this video will aid adults in understanding the big picture of literacy and how their immediate learning of orthographical concepts will move them ever forward on the continuum of word knowledge.

In conclusion, this study provides insight on adult learners' spelling. I have learned that adult spelling errors can be categorized into the same five developmental stages applicable to younger students based on their orthographic knowledge. I have also realized that many adults are motivated to improve their spelling and are willing to try new methods, though some adults are not able to commit to long-term intervention. Word Study just may be the avenue to assist them in learning about word features and increase their ability to teach themselves regardless of the length of the intervention. Word Study was well received by the adults and was shown to positively affect their self-perceptions.

\section{REFERENCES}

Bear, D.R., Invernizzi, M., Templeton, S., \& Johnston, F. (2000). Words their way [Motion picture]. United States: Merrill Prentice Hall.

Bear, D.R., Invernizzi, M., Templeton, S., \& Johnston, F. (2004). Words their way. Upper Saddle River, NJ: Merrill Prentice Hall.

Bear, D.R., Truex, P., \& Barone, D. (1989). In search of meaningful diagnosis: Spelling-by-stage assessment of literacy proficiency. Adult Literacy and Basic Education, 13, $167-185$. 
Bloodgood, J.W. (1991). A new approach to spelling instruction in language arts programs. The Elementary School Journal, 92, 203-211.

Chall, J. S. (1994). Patterns of adult reading. Learning Disabilities: A Multidisciplinary Journal, 5(1), 29-33.

Chomsky, C. (1970). Invented spelling in the open classroom. Word, 27, 499-518.

Ehri, L.C. (1997). Learning to read and learning to spell are one and the same, almost. In C.A. Perfetti, L. Rieben, \& M. Fayol (Eds.), Learning to spell: Research, theory and practice across languages (pp. 237-269). Mahwah, NJ: Erlbaum.

Ganske, K. (2001). Word journeys. New York: Guilford.

Gill, C.H. (1996). "Why do they get it on Friday and misspell it on Monday?" Teachers inquiring about their students as spellers. Language Arts, 73, 89-96.

Greenberg, D. (1998). Betsy: Lessons learned from working with an adult nonreader. Journal of Adolescent \& Adult Literacy, 41, 252-261.

Hanlon, M.M., \& Cantrell, R.J. (1999). Teaching a learning disabled adult to spell: Is it ever too late? Journal of Adolescent \& Adult Literacy, 43, 4-11.

Hanna, P.R., Hanna, J.S., Hodges, R.E., \& Rudorf, H. (1966). Phoneme-grapheme correspondences are cues to spelling improvement. Washington, DC: U.S. Department of Health, Education, and Welfare.

Henderson, E.H., \& Beers, J. (Eds.). (1980). Developmental and cognitive aspects of learning to spell: A reflection of word knowledge. Newark, DE: International Reading Association.

Henderson, E.H., \& Templeton, S. (1986). A developmental perspective of formal spelling instruction through alphabet, pattern, and meaning. The Elementary School Journal, 86, 304-316.
Kitz, W.R. (1988). Adult literacy: A review of the past and a proposal for the future. Remedial and Special Education, 9, 44-50.

Morris, D., Blanton, L., Blanton, W.E., \& Perney, J. (1995). Spelling instruction and achievement in six classrooms. The Elementary School Journal, 96, 145-162.

Padak, N.D., \& Padak, G.M. (1987). Guidelines and a holistic method for adult basic reading programs. Journal of Reading, 30, 490-496.

Read, C. (1971). Preschool children's knowledge of English phonology. Harvard Educational Review, 41, 1-34.

Roehler, L.R., \& Cantlon, D.J. (1997). Scaffolding: A powerful tool in social constructivist classrooms. In K. Hogan \& M. Pressley (Eds.), Scaffolding student learning: Instructional approaches and issues (pp. 6-42). Cambridge, MA: Brookline.

Schlagal, R. (2002). Classroom spelling instruction: History, research, and practice. Reading Research and Instruction, 42, 44-57.

Sheffield, B. (2003). An excerpt from handwriting: a neglected cornerstone of literacy. In Zaner-Bloser, Handwriting research and resources: A guide to curriculum planning (pp. 19-24). New York: Zaner-Bloser.

Templeton, S., \& Morris, D. (1999). Questions teachers ask about spelling. Reading Research Quarterly, 34, 102-112.

Viise, N.M. (1996). A study of the spelling development of adult literacy learners compared with that of classroom children. Journal of Literacy Research, 28, 561-587.

Worthy, J., \& Viise, N.M. (1996). Morphological, phonological, and orthographic differences between the spelling of normally achieving and basic literacy skills. Reading and Writing: An Interdisciplinary Journal, 8, 139-159.

Zaporozhets, A., \& Elkonin, D. (1971). Psychology of preschool children. Cambridge, MA: MIT Press.

Zutell, J. (1978). Some psycholinguistic perspectives on children's spelling. Language Arts, 55, 844-850. 